\title{
Numerical investigation of cu-water nanofluid in a differentially heated square cavity with conducting solid square cylinder at center
}

\author{
Bishwajit Sharma*, Basant Kumar, Rabindra Nath Barman \\ Department of Mechanical Engineering, National Institute of Technology Durgapur, West Bengal 713209, India
}

Corresponding Author Email: sharmabishwajit93@gmail.com

https://doi.org/10.18280/ijht.360238

Received: 22 December 2017

Accepted: 6 April 2018

\section{Keywords:}

fluent, lid driven cavity, nanofluids, nanoparticles, conducting cylinder

\begin{abstract}
The Present study is an endeavor to laminar flow heat transfer of $\mathrm{Cu}$-water nanofluid inside a square cavity. The cavity is heated by different length heaters with isothermal boundary condition placed symmetrically on two adjacent sides. The moving lid has low temperature and rest of the boundaries are insulated. A thermally conducting solid cylinder is placed at the center of the cavity. The effect of different parameters, nanoparticles volume fraction $(0-$ 0.08), Richardson Number (0.01-10) on the fluid flow and temperature fields have been studied. The average Nusselt number increases with the increase in nanoparticle concentration and size of the heater. The effect of concentration of nanoparticles reduces with decrease in Richardson Number.
\end{abstract}

\section{INTRODUCTION}

From past decades, the need for efficient cooling method has been felt for various industrial purposes. Energy transport is the key phenomenon behind the success of any heating or cooling equipment. At room temperature, the thermal conductivity of metallic particles is hundred times more than that of base fluid resulting in the significant enhancement in thermal properties of these mixtures as compared to conventional heat transfer fluids. Although the solid micro particles show a considerable improvement in heat transfer but their applications are limited as they settle rapidly causing severe pressure drop, erosion, and clogging of the flow channels. Nanofluids having particle size less than 100 nanometer are expected to behave as pure fluid resulting in reduction of pressure drop across channel. This happens as the particle size is below the critical length scale of fluid exhibiting the properties similar to that of conventional fluids. The surface area to volume ratio for the nanoparticles are very large resulting in superior thermal, magnetic, electrical and optical properties.

Brinkman [1] published a revolutionary article depicting an expression for the viscosity of the suspension and solution of a continuous medium. Maxwell [2] showed that the effective thermal conductivity of the fluid-solid mixture increases with increase in the volume fraction of solid particles. Choi [3] first time utilized nanoparticles to enhance the effective thermal conductivity of nanofluids thus improving the heat exchanger pumping power. Chao et al. [4] and Chu et al. [5] studied the thermal performance of nano fluids both experimentally and numerically. They studied the effect of varying size and location of heater with different aspect ratio of the cavity. The non-dimensional parameters like Grashoff number, Prandtl number, Reynolds number, Richardson number, Rayleigh number etc. play a very significant role for heat transfer related multi physics applications. The effect of varying Raleigh number was numerically studied by Oztop and abu-nada [6] who investigated the heat transfer and fluid flow inside the cavity with Rayleigh number $1000<\mathrm{Ra}<10000$, aspect ratio of cavity $0.5-2$ and different heater sizes with different locations and found that the cavity with low aspect ratio was thermally more efficient than with high aspect ratio. Further many studies were carried out using different heater sizes along with their different locations [7-14].

Hasnaoui et al. [7] included rectangular cavities with aspect ratio of $1-2$, dimensionless heater size $0.06-1$ and position of heater with offset non-dimensional distance $-0.6-0.7$ with respect to vertical symmetry line of cavity. Computations by Ahmed and Yovanovich [8] were carried out for heater offset distance of $0.25-1$.

Thermal conductance was analyzed for $\mathrm{Ra}=0$ and an analytical conduction solution was found out. For natural convection, Türkoglu and Nuri [9] proposed that the heater should be placed closer to the bottom wall of enclosure and cooler should be placed closer to the top wall in order to increase mean Nusselt Number. The convective heat transfer in copper water nanofluid with varying magnetic field was analyzed by Ahrara et al. [19]. The lid driven cavity is a classical and important geometry which helps to observe the fundamental characteristics and its potential to predict the multiphysics. This article is an attempt to study the performance of two different sized heaters placed at different locations inside the cavity by observing wall heat flux for different cases with varying nanoparticles concentration.

\section{MATHEMATICAL FORMULATION MODELLING}

AND

The two-dimensional steady flow is considered inside the square cavity along with the boundary conditions as shown in figure. 1 . The square cavity of length $\mathrm{L}$ has $\mathrm{Cu}-\mathrm{H}_{2} \mathrm{O}$ nanofluid with the conducting solid square cylinder of each side $0.2 \mathrm{~L}$ placed at the center. A Cartesian system is chosen so that the 
origin lies at the bottom left corner of the cavity. Two heaters of varying length $(0.2 \mathrm{~L} \leq \mathrm{b} \leq 0.6 \mathrm{~L})$ and maintained at constant hot temperature $T_{h}$ are located at the middle of left and bottom sides of the cavity. The right lid is at cold temperature and moving with velocity $U_{o}$. Rest all the walls of cavity are insulated. The nanoparticles are assumed to have uniform shape and size and are at thermal equilibrium with base fluid so that they flow with same velocity.

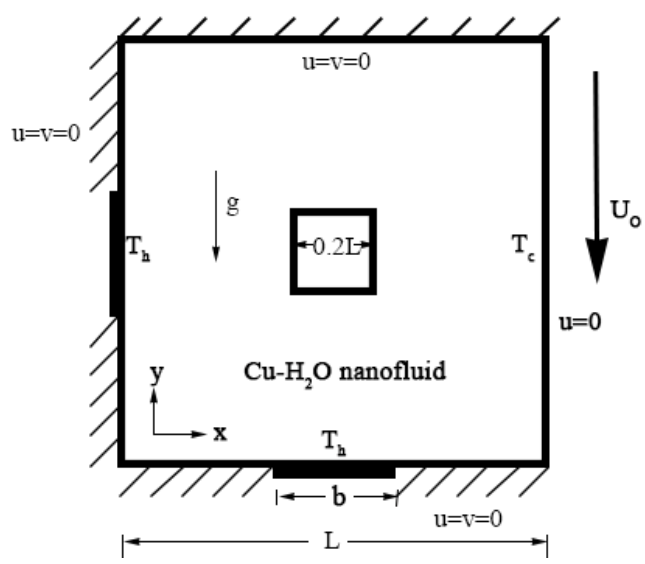

Figure 1. Schematic of cavity with conducting square solid cylinder

The properties of base fluid, nanoparticle and square conducting cylinder is shown in Table 1.

Table 1. Properties of base fluid and nanoparticles

\begin{tabular}{|c|ccc|}
\hline & $\begin{array}{c}\text { Base } \\
\text { Fluid }\end{array}$ & $\begin{array}{c}\text { Nano } \\
\text { particle }\end{array}$ & $\begin{array}{c}\text { Conducting } \\
\text { square } \\
\text { cylinder }\end{array}$ \\
\hline Material & water & Copper & Titanium \\
Density & 998.2 & 8978 & 4850 \\
Specific heat $(\mathrm{J} / \mathrm{kg}-\mathrm{K})$ & 4182 & 381 & 544.25 \\
Thermal & 0.6 & 387.6 & 7.44 \\
conductivity $(\mathrm{w} / \mathrm{m}-\mathrm{K})$ & & & \\
\hline
\end{tabular}

Assuming the steady and incompressible flow with Boussinesq approximation the non-dimensional differential transport equations of mass, momentum and energy can be written as follows:

For nanofluid

$\frac{\partial U}{\partial X}+\frac{\partial V}{\partial Y}=0$

$U \frac{\partial U}{\partial X}+V \frac{\partial U}{\partial Y}=-\frac{\partial P}{\partial X}+\frac{1}{\operatorname{Re}}\left(\frac{\partial^{2} U}{\partial X^{2}}+\frac{\partial^{2} U}{\partial Y^{2}}\right)$

$U \frac{\partial V}{\partial X}+V \frac{\partial V}{\partial Y}=-\frac{\partial P}{\partial Y}+\frac{1}{\operatorname{Re}}\left(\frac{\partial^{2} V}{\partial X^{2}}+\frac{\partial^{2} V}{\partial Y^{2}}\right)+\operatorname{Ri} \theta$

$U \frac{\partial \theta}{\partial X}+V \frac{\partial \theta}{\partial Y}=\frac{1}{\operatorname{Re} \operatorname{Pr}}\left(\frac{\partial^{2} \theta}{\partial X^{2}}+\frac{\partial^{2} \theta}{\partial Y^{2}}\right)$

For solid conducting square cylinder $\frac{\partial^{2} \theta_{s}}{\partial X^{2}}+\frac{\partial^{2} \theta_{s}}{\partial Y^{2}}=0$

where the dimensionless variables can be written as

$X=\frac{x}{L}, \quad Y=\frac{y}{L}, \quad U=\frac{u}{U_{0}}, \quad V=\frac{v}{U_{0}}, \quad \theta=\frac{\left(T-T_{c}\right)}{\left(T_{h}-T_{c}\right)}$,

$\theta_{s}=\frac{\left(T_{s}-T_{c}\right)}{\left(T_{h}-T_{c}\right)}, P=\frac{(p+\rho g y)}{\rho U_{0}^{2}} L^{2}$

$\operatorname{Re}=\frac{\rho U_{0} L}{\mu}, R i=\frac{G r}{\operatorname{Re}^{2}}, G r=\frac{g \beta \Delta T L^{3}}{v^{2}}, \operatorname{Pr}=\frac{\mu C_{p}}{k}$

If $\mathrm{n}$ is the normal direction then the boundary conditions for different domains can be written as

For fluid domain:

$$
\begin{array}{lrll}
0 \leq X \leq \frac{(L-b)}{2 L} & \mathrm{Y}=0 & \mathrm{U}=\mathrm{V}=0 & \frac{\partial \theta}{\partial n}=0 \\
\frac{(L-b)}{2 L} \leq X \leq \frac{(L+b)}{2 L} & \mathrm{Y}=0 & \mathrm{U}=\mathrm{V}=0 & \theta=1 \\
\frac{(L+b)}{2 L} \leq X \leq 1 & \mathrm{Y}=0 & \mathrm{U}=\mathrm{V}=0 & \frac{\partial \theta}{\partial n}=0 \\
\mathrm{X}=0 & 0 \leq Y \leq \frac{(L-b)}{2 L} & \mathrm{U}=\mathrm{V}=0 & \frac{\partial T}{\partial n}=0 \\
\mathrm{X}=0 & \frac{(L-b)}{2 L} \leq Y \leq \frac{(L+b)}{2 L} & \mathrm{U}=\mathrm{V}=0 & \theta=1 \\
\mathrm{X}=0 & \frac{(L+b)}{2 L} \leq Y \leq 1 & \mathrm{U}=\mathrm{V}=0 & \frac{\partial \theta}{\partial n}=0 \\
0 \leq \mathrm{X} \leq 1 & \mathrm{Y}=1 & \mathrm{U}=\mathrm{V}=0 & \frac{\partial \theta}{\partial n}=0 \\
\mathrm{X}=1 & 0 \leq \mathrm{Y} \leq 1 & \mathrm{U}=0, \mathrm{~V}=1 & \theta=0
\end{array}
$$

For conducting solid square cylinder,

$\left(\frac{\partial \theta}{\partial n}\right)_{f}=\left(\frac{\partial \theta}{\partial n}\right)_{s}$

Prandtl number for $\mathrm{Cu}-\mathrm{H}_{2} \mathrm{O}$ nanofluid is taken as 6.2 as discussed by R K Tiwari and M K Das. The effective density of nanofluid is given by expression

$$
\rho_{n f}=(1-\phi) \rho_{f}+\phi \rho_{s}
$$

and the heat capacitance is given by Xuan and Li

$$
\left(\rho C_{p}\right)_{n f}=(1-\phi)\left(\rho C_{P}\right)_{f}+\phi\left(\rho C_{p}\right)_{s}
$$

The effective thermal conductivity calculated by the Maxwell-Garnett's approximation model. It is assumed that the nanofluid has spherical particle suspension.

$\frac{k_{e f f}}{k_{f}}=\frac{\left(k_{s}+2 k_{f}\right)-2 \phi\left(k_{f}-k_{s}\right)}{\left(k_{s}+2 k_{f}\right)+\phi\left(k_{f}-k_{s}\right)}$

The Nusselt number of nanofluid is calculate along the cold moving lid and is expected to depend on various parameters 
such as heat capacitance of particles and base fluids, volume fraction of nanoparticles, viscosity of nanofluid, etc. So, the local Nusselt number can be found out as

$$
N u=\frac{Q}{Q_{\text {conduction }, n f}}=-\frac{-\left(k_{\text {eff }}\right)_{\text {stagnant }}}{k_{n f}} \frac{\partial T}{\partial X}
$$

The average Nusselt number calculated at the cold wall is given by

$$
\overline{N u}=\int_{0}^{1} N u \cdot d y
$$

\section{NUMERICAL ANALYSIS AND VALIDATION}

The governing equations are discretized and solved numerically by finite volume method based CFD package Fluent ${ }^{16}$. Semi-implicit method for pressure linked equation (SIMPLE) is used to couple the momentum and continuity equation the velocity field is updated by solving the momentum equation using the calculated value of pressure and velocity. The convective terms are spatially discretized using quadratic upstream interpolation convective kinetics (QUICK) and a central difference scheme is applied to discretization of convective terms. The convergence criteria are set to be $10^{-10}$ and $10^{-12}$ for continuity and energy equations respectively. A non-uniform grid is generated with refined mesh closer to the walls which is shown in figure 2.

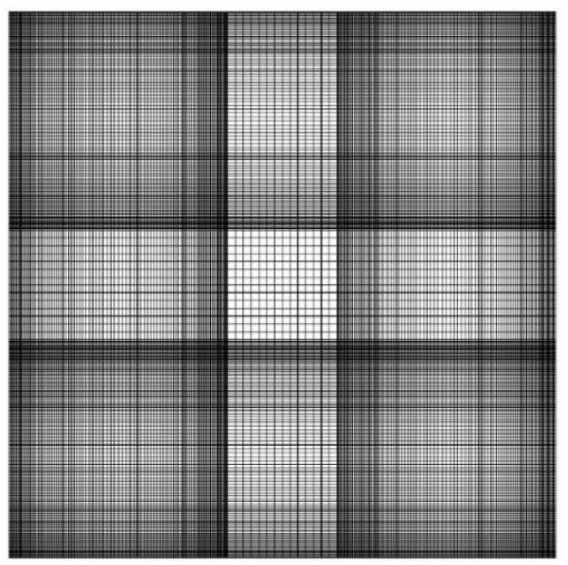

Figure 2. Grid distribution in the computational domain

The grid independency is checked by varying different number of grids and calculating the Nusselt number at respective grid count. The case is solved for $\mathrm{Ri} 0.1$ and $\mathrm{Gr} 10^{4}$ with six different mesh sizes. The Nusselt number distribution is represented with $21 \times 21,51 \times 51,81 \times 81,101 \times 101,125 \times 125$ and $151 \times 151$. The $\mathrm{Nu}$ seems to vary within $0.002 \%$ from $125 \times 125$ grids. So, all the further investigations are conducted at $125 \times 125$ nodes. Figure 3 shows the results obtained after performing computation at these six grid configurations. The present numerical scheme is compared with the work of Talebi et al. ${ }^{17}$ and G. De Vahl Devis ${ }^{18}$ for the purpose of model validation and a very good agreement is found with their results.

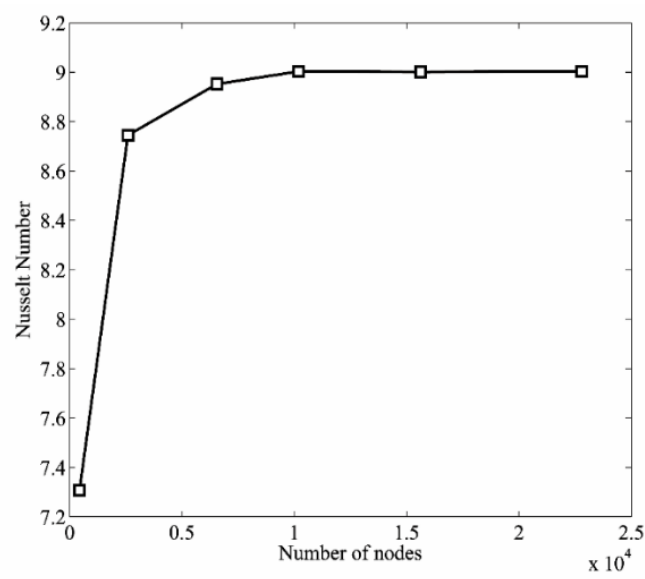

Figure 3. Grid study

\section{RESULTS AND DISCUSSIONS}

Computations are carried out with three different boundary conditions inside the domain which are adiabatic, isothermal and conductive. The details about the boundary conditions are discussed in the mathematical modeling part earlier. The flow inside the cavity is greatly influenced by the Richardson number which is taken as important governing parameter for our case. It also affects the temperature distribution (isotherms) inside the cavity. Total 60 cases are solved with varying heater sizes, $\mathrm{b}=0.2,0.4$ and 0.6 with four different Richardson Number from 0.01 to 10 . The cases were analyzed using five different nanoparticle concentrations, $\phi=0,0.01,0.03,0.05$ and 0.08 . The lid has velocity in only negative $y$-axis for all the cases. Stream lines and Isotherms for different $\mathrm{Ri}$ with varying heater sizes are shown in figure 4, figure 5, figure 6 and figure 7. As $\mathrm{Ri}$ increases the Re reduces and the velocity of lid decreases. Figure 4 shows the effect of $\mathrm{Ri}=0.01$ in the flow field and temperature distribution.

Table 2. Comparison of local and average Nusselt number with Talebi et al. [17] and De vahl Devis [18]

\begin{tabular}{cccccc}
\hline Ra & $\begin{array}{c}\text { Talebi et. al } \\
\text { Average Nusselt } \\
\text { Number }(\mathrm{Nu})\end{array}$ & $\begin{array}{c}\text { De Vahl Devis } \\
\text { Average Nusselt } \\
\text { Number }(\mathrm{Nu})\end{array}$ & $\begin{array}{c}\text { G. De Vahl Devis } \\
\text { Local Maximum Nusselt } \\
\text { Number (Nu) }\end{array}$ & $\begin{array}{c}\text { Present } \\
\text { study }\end{array}$ & Error \% \\
\hline $1.47 \times 10^{4}$ & 6.11 & - & - & 6.08 & 0.49 \\
$1.47 \times 10^{5}$ & 7.22 & - & - & 7.25 & 0.41 \\
$1.47 \times 10^{6}$ & 11.61 & - & - & 11.8 & 1.61 \\
$1 \times 10^{4}$ & - & 4.242 & - & 2.27 & 1.42 \\
$1 \times 10^{5}$ & - & 8.923 & - & 4.62 & 2.16 \\
$1 \times 10^{6}$ & - & - & 3.545 & 9.06 & 1.51 \\
$1 \times 10^{4}$ & - & - & 7.761 & 7.59 & 1.38 \\
$1 \times 10^{5}$ & - & - & 18.076 & 18.7 & 2.01 \\
$1 \times 10^{6}$ & - & & & & 3.79 \\
\hline
\end{tabular}




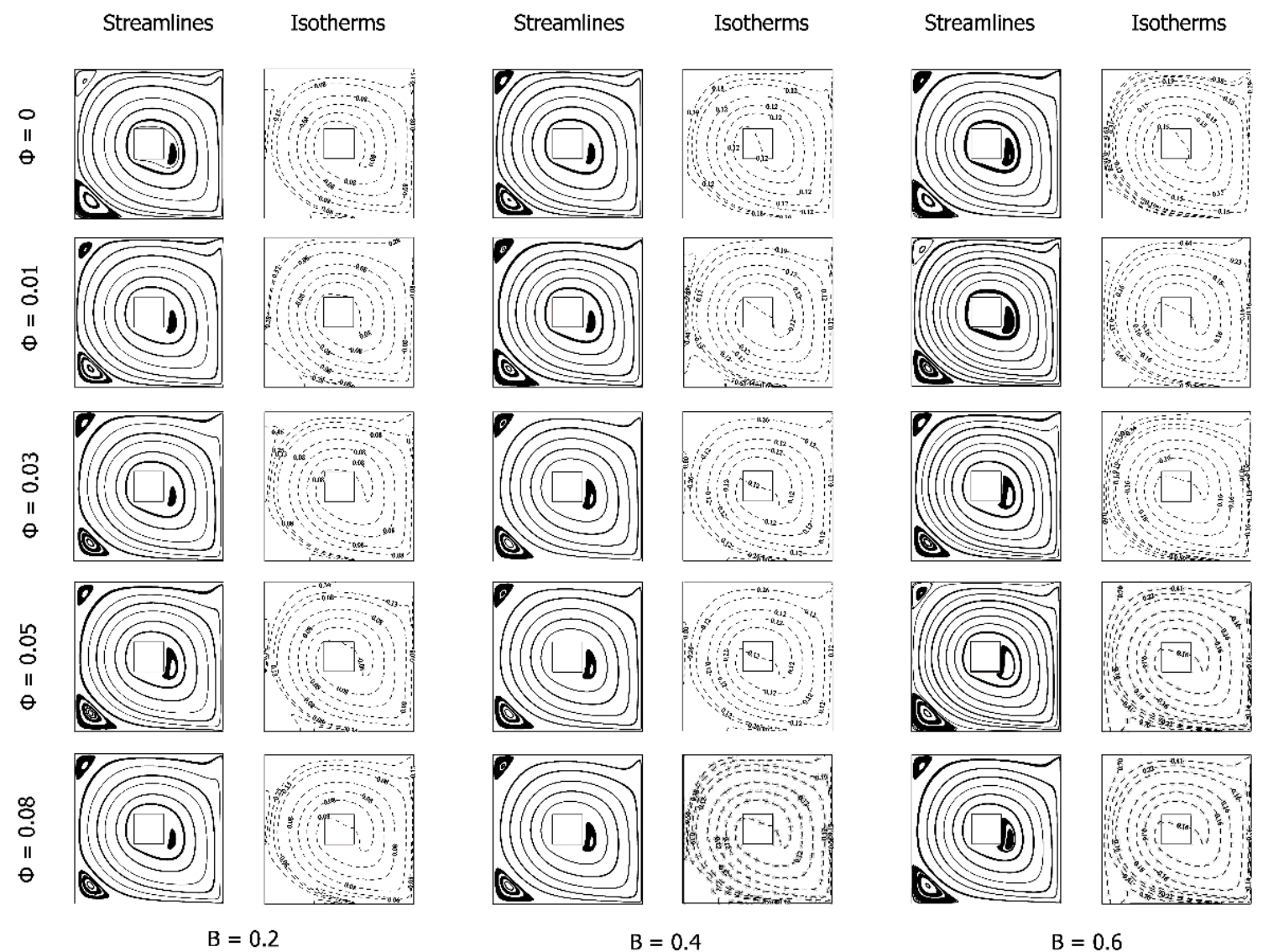

Figure 4. Streamlines and Isotherms for different heater size and $\phi$ at $\mathrm{Ri}=0.01$
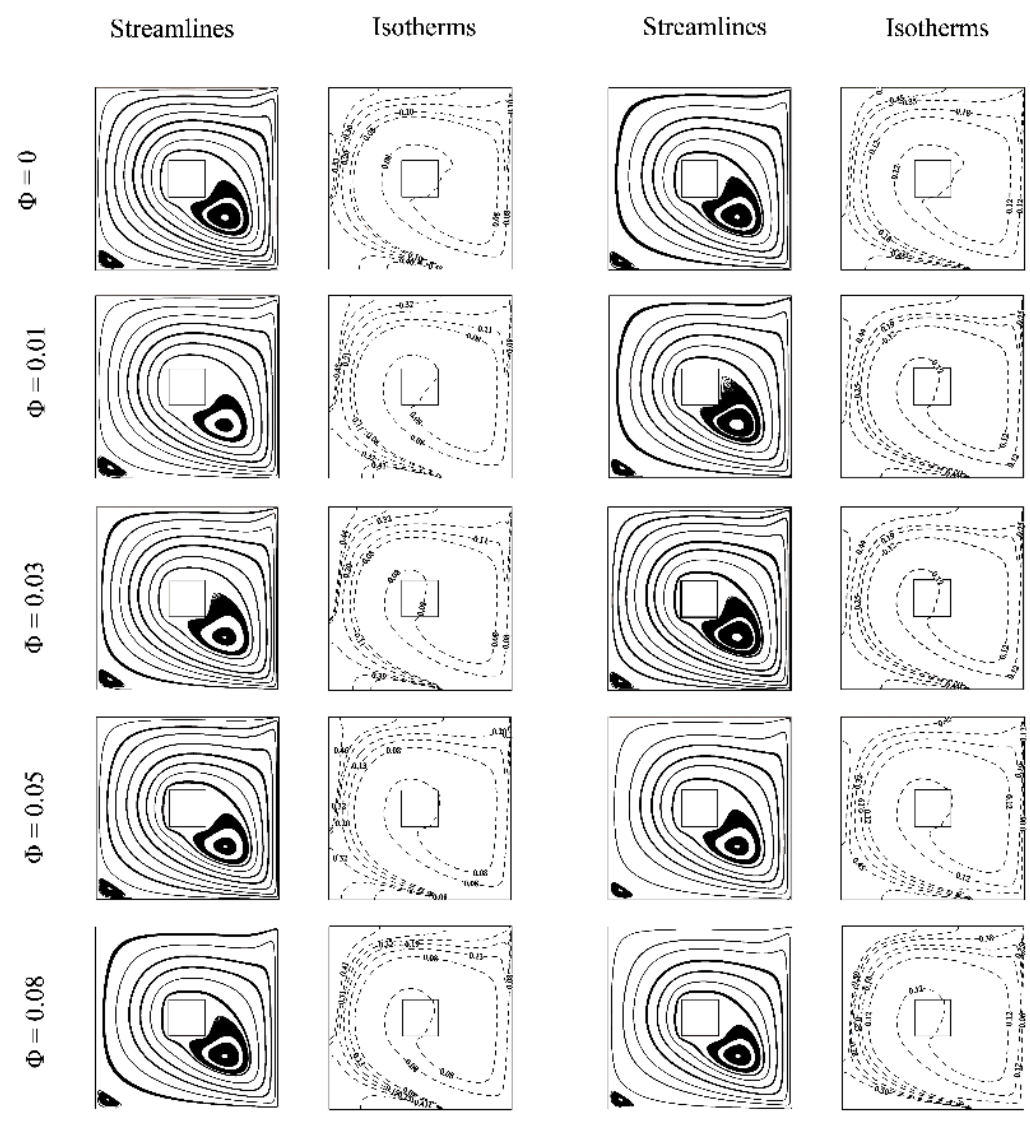

$\mathrm{B}=0.2$

$\mathrm{B}=0.4$

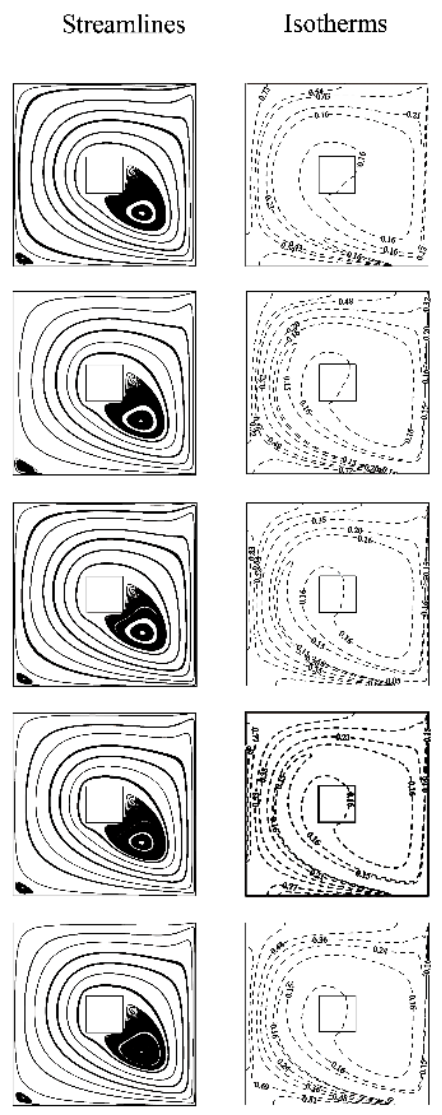

$\mathrm{B}=0.6$

Figure 5. Streamlines and Isotherms for different heater size and $\phi$ at $\mathrm{Ri}=0.1$ 


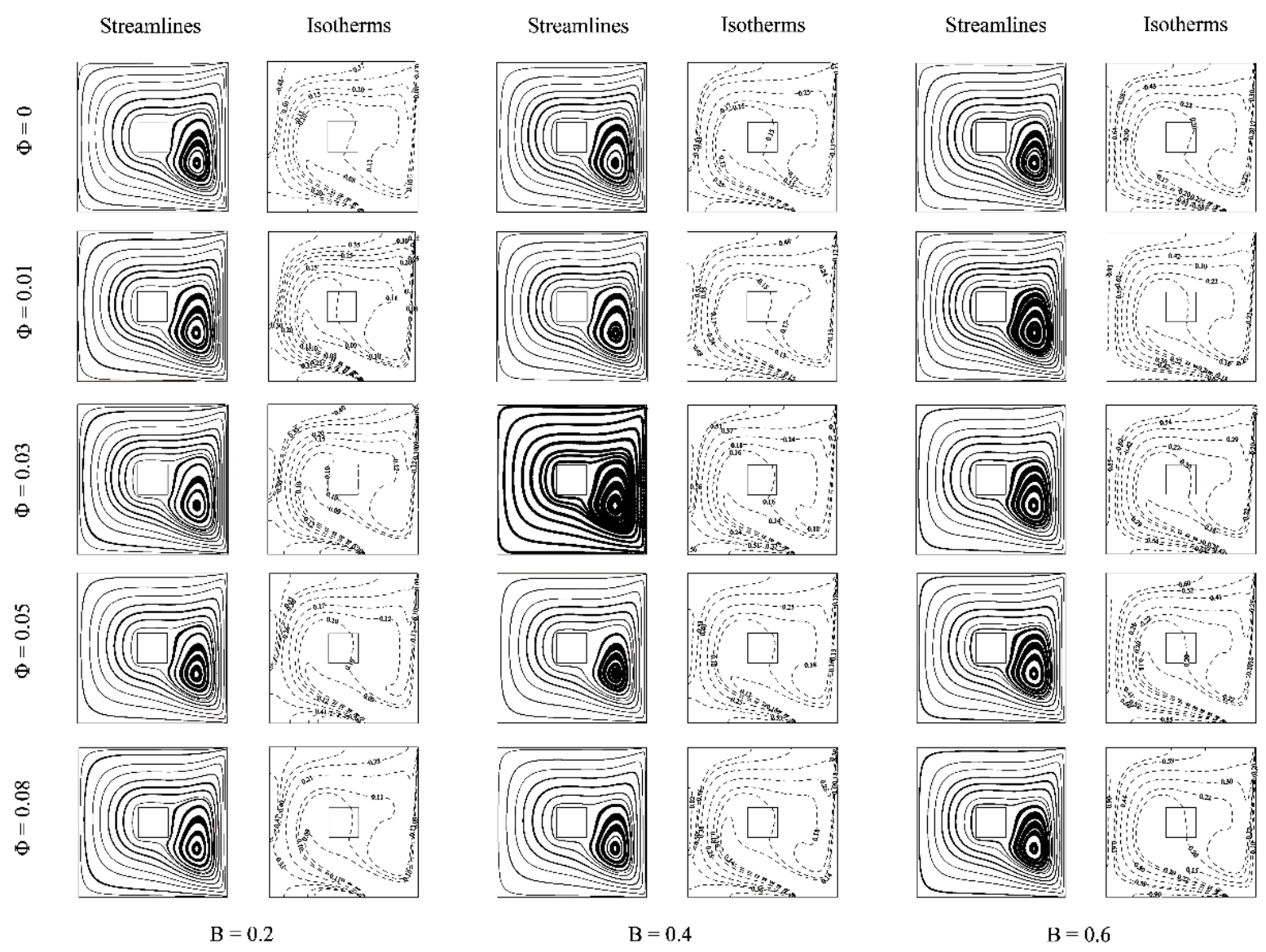

Figure 6. Streamlines and Isotherms for different heater size and $\phi$ at $\mathrm{Ri}=1$

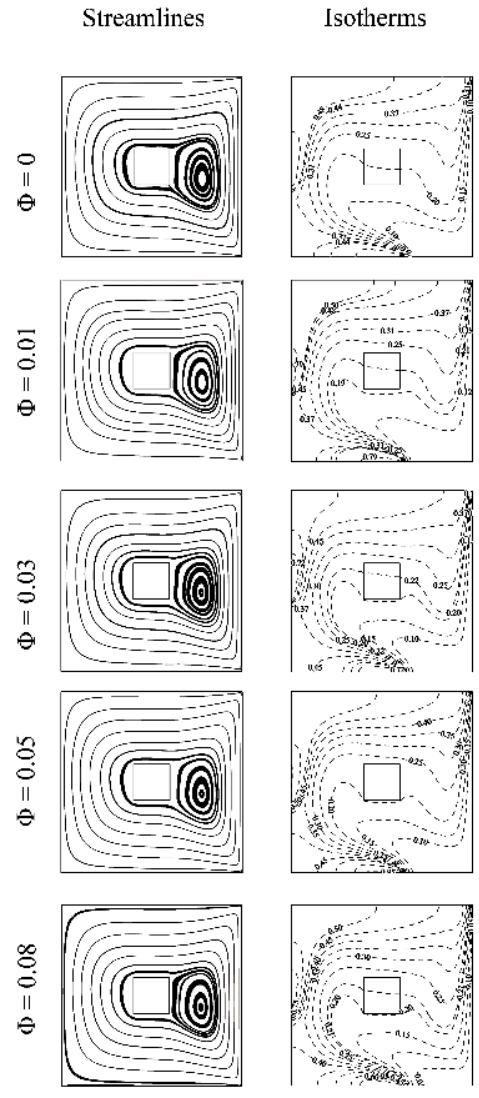

$\mathrm{B}=0.2$

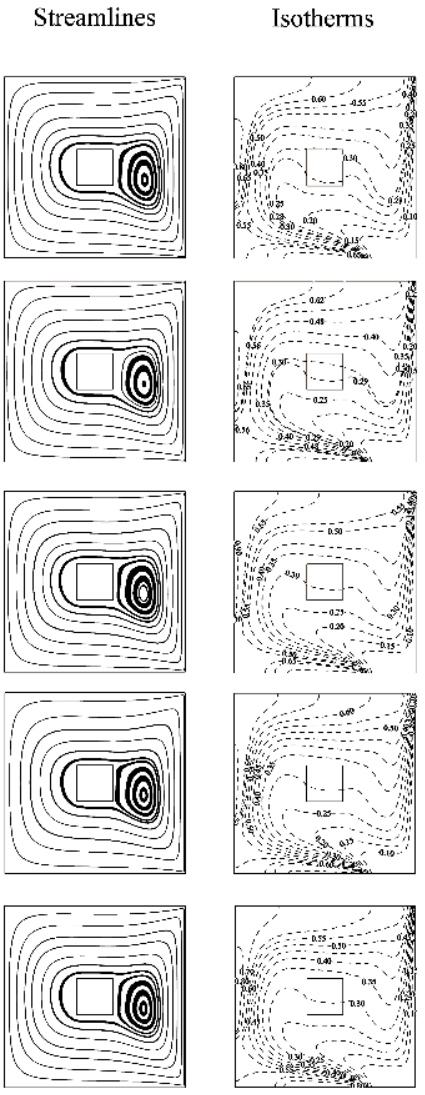

$\mathrm{B}=0.4$

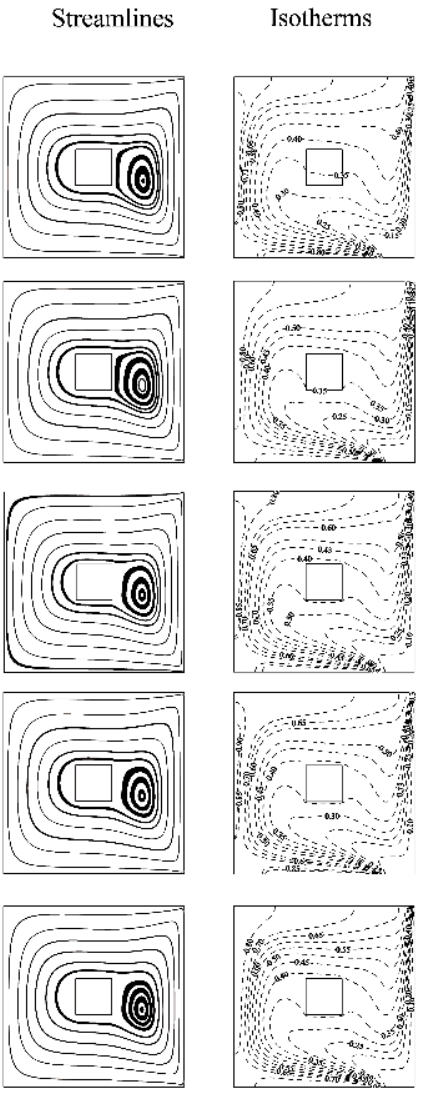

$\mathrm{B}=0.6$

Figure 7. Streamlines and Isotherms for different heater size and $\phi$ at $\mathrm{Ri}=10$ 


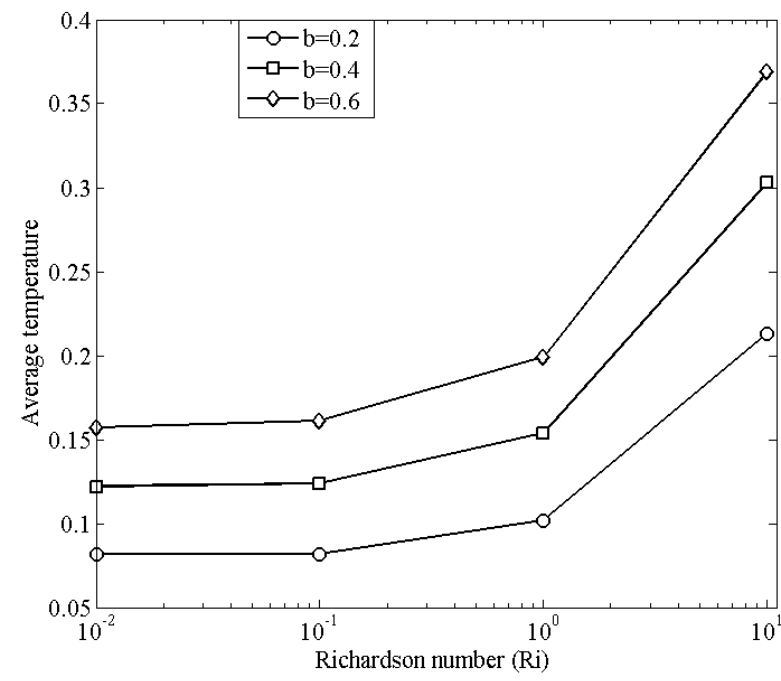

Figure 8. Average non-dimensional temperature of square cylinder for different $\mathrm{b}$ and $\mathrm{Ri}$ at $\phi=0.03$

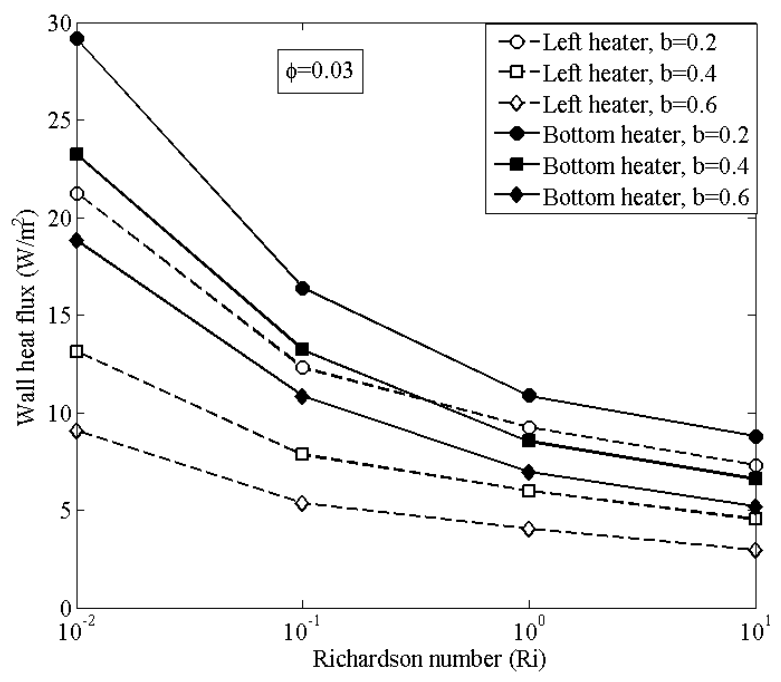

Figure 9. Wall heat flux with varying Richardson number at $\phi=0.03$
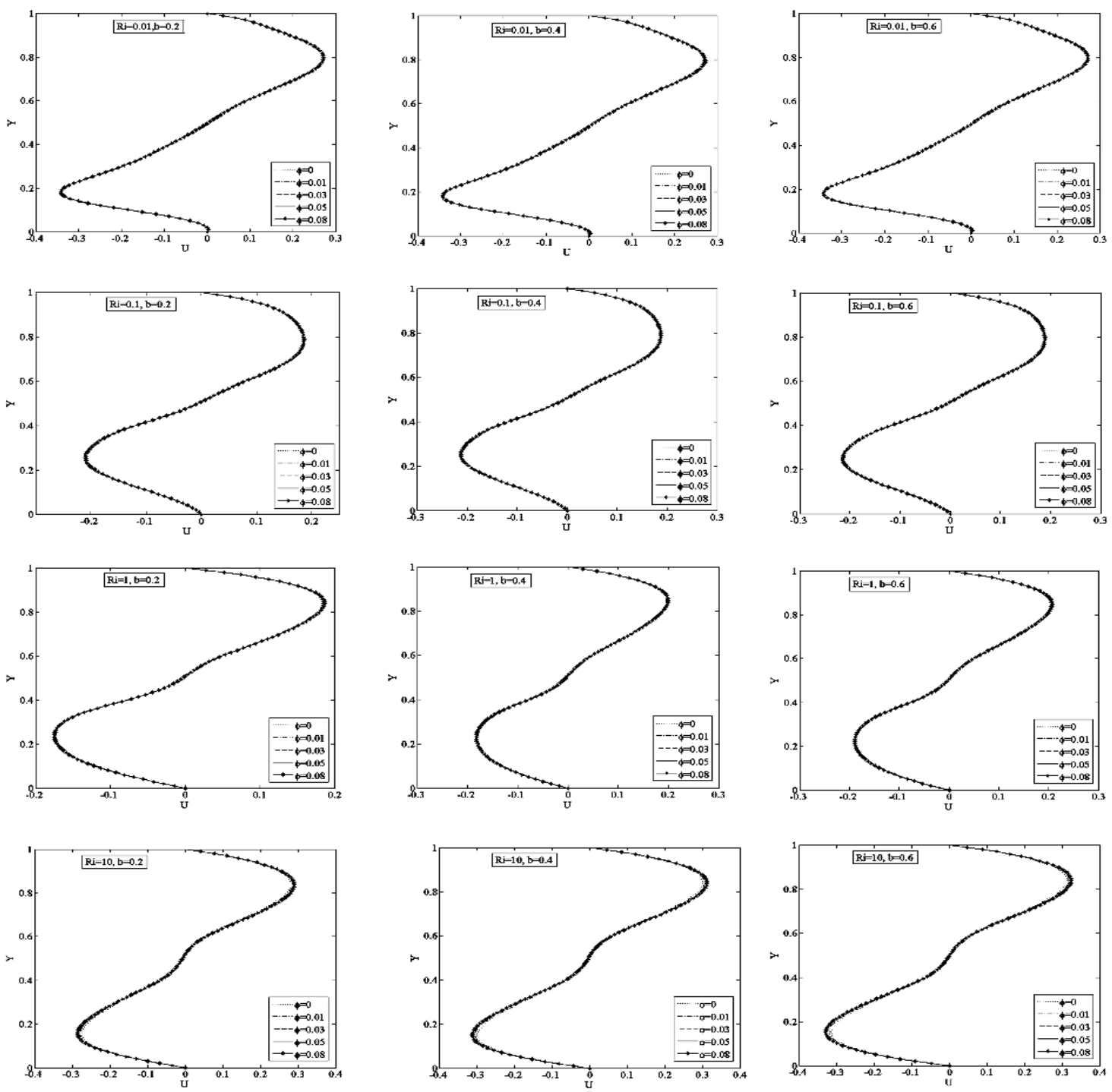

Figure 10. Variation of non-dimensional horizontal velocity component along the vertical line at $x=0.3$ with $\phi$ for different heater size and $\mathrm{Ri}$

A low Ri corresponds to a high Re and subsequently makes forced convection dominant. The streamline pattern is almost identical for all the nanoparticle concentration due to the weaker natural convective heat transfer. As the concentration of nanofluid increases the flow field inside the cavity gets slightly affected by the natural convection. The lid movement 
in -y direction causes a Clock Wise $(\mathrm{CW})$ rotation of the fluid inside the cavity. The conductive square cylinder restricts the fluid flow but allows the heat to flow through it. As a result, the flow gets accelerated due to blockage provided by the cylinder and closed isocontours can be seen over the bottom heater which exhibits similar trend around the left heater also. Two small Counter Clock Wise (CCW) rotating edddies can be seen at the left upper and left bottom corners. Small CW rotating eddies can be seen besides the right edge of the square conducting cylinder which is induced by the restriction imposed on the flow field by it.

At $\mathrm{Ri}=0.1$, figure 5 , a similar trend is observed but the size of eddies located at right edge of cylinder increases and shifts slightly towards the bottom right corner. The size of two eddies at top-left and bottom-left corners of the cavity are reduced. This is due to the decrease in advection as Reynolds number decreases.

Figure 6 and figure 7 are showing similar stream line pattern with increase in the size of $\mathrm{CW}$ rotating eddies upto $\mathrm{Ri}=1$ but again reduces for $\mathrm{Ri}=10$. The corner $\mathrm{CCW}$ rotating eddies are totally eliminated due to the high Richardson number and low velocity inside the cavity. At high $\mathrm{Ri}$ the isotherms near the bottom heater are denser and steeper with respect to its surface. As $\mathrm{Ri}$ increases the flow field approaches to the natural convective heat transfer. For $\mathrm{Ri} \geq 1$ the natural convective heat transfer dominates and the isotherms near to the bottom heater surface become less steeper causing the rise in average temperature of conducting square cylinder.

Figure 8 shows the average non-dimensional temperature of square conducting cylinder at different Richardson number and $\phi=0.03$. It can be noted that the average temperature of the cylinder increases with increase in the size of heater and
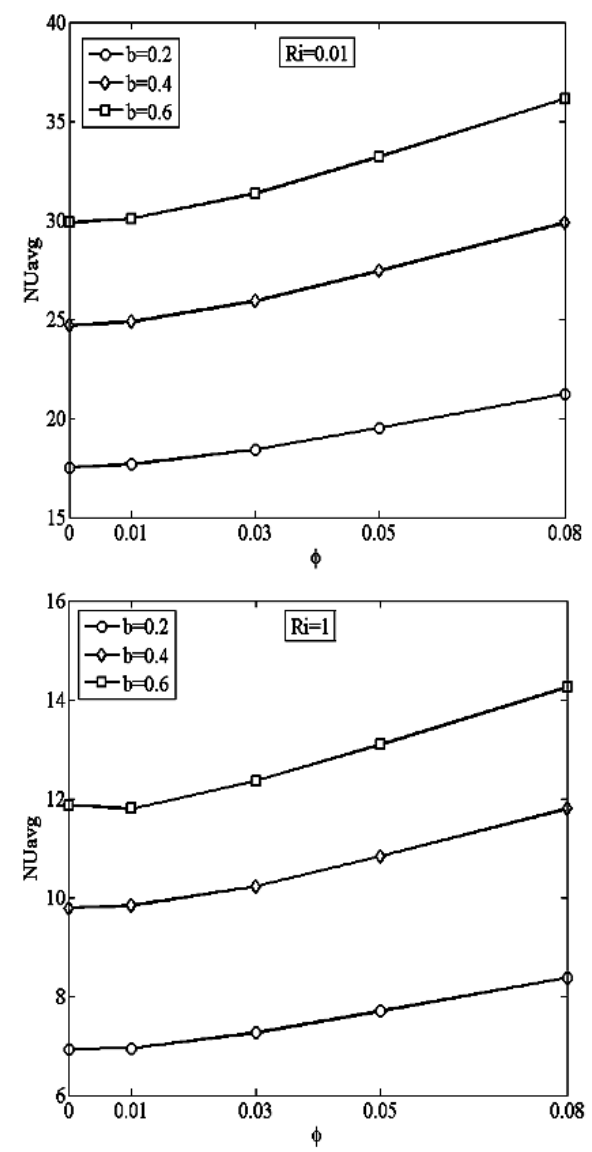

Richardson number. For $\mathrm{Ri} \leq 0.1$ the average temperature of cylinder is approximately same for heater having $b=0.2$ and a very slight increase in value for $b=0.4$ and $b=0.6$ because of prevailing forced convection.

It is important to analyze the performance of both heaters and compare their role in the process of heat transfer. Figure 9 is an attempt to observe the average wall heat flux from both heaters to the fluid domain for different heater sizes. It can be seen clearly that bottom heater allows more heat exchange to the fluid domain as compared to the left heater for all cases. With increase in Ri the heat flux is getting reduced due to the dominance of natural convection. At lower Ri high velocity of fluid results in a larger temperature gradient near to the heater surface which causes the higher value of heat flux.

Natural convection $(\mathrm{Ri} \geq 1)$ is responsible for the rise in average temperature of the cylinder body because of direct heat transport from the heater itself and it can be analyzed by comparing the density and alignment of isotherms near the heater and cylinder walls.

Figure 10 shows the dimensionless horizontal component of velocity at $\mathrm{x}=0.3$ for different heater sizes and $\mathrm{Ri}$. The dimensionless velocity is 0 at the bottom and top wall. The circulation of the fluid inside the cavity is causing the curve to be symmetrical about $\mathrm{Y}=0.5$. as the natural convection dominates at high Richardson number the circulation decreases and hence the dimensionless horizontal velocity also decreases. As the concentration of nanoparticle increases it leads to the enhancement in viscosity of nanofluids and thus the velocity decreases.

For a specific $\mathrm{Ri}$ and heater size, the contribution of nanoparticles is insignificant towards the motion of fluid inside the cavity.
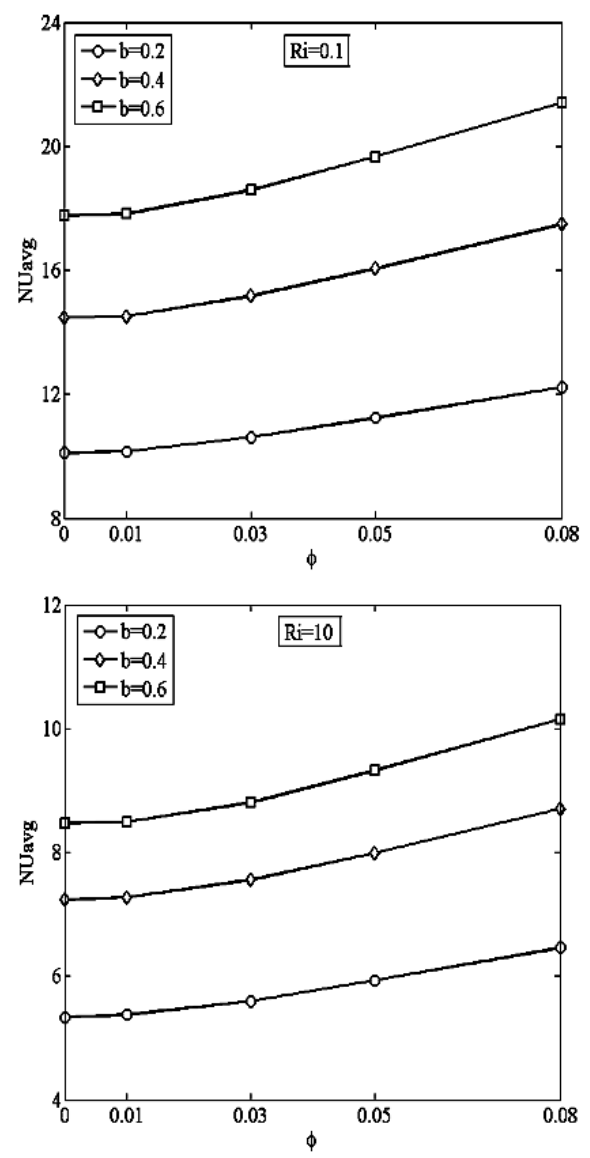

Figure 11. Variation of average Nusselt number of the cold moving wall with $\phi$ for different heater size and Ri 
The variation of average Nusselt number with respect to the nanoparticle concentration and Richardson number at each heater size is shown in figure 11. It is seen that the Nusselt number increases linearly with volume fraction of nanoparticle as addition of nanoparticle causes the increase in thermal conductivity of nanofluids. Ri plays a significant role in the enhancement of the thermal performance of the nanofluid as it increases with the decrease in the Ri. As Ri increases the reduction in the temperature gradient near to the heated wall surface it causes reduction in the convective heat transfer and hence the Nu decreases. Furthermore, the Nusselt number also increases with increase in the heater size. Therefore, the overall enhancement in heat transfer takes place with addition of nanoparticles and reducing the Richardson number.

\section{CONCLUSION}

Heater size and Richardson number are considered as important governing parameter to analyze the thermal performance of $\mathrm{Cu}-\mathrm{H}_{2} \mathrm{O}$ nanofluid in the lid driven cavity with variation in volume fraction from 0 to $8 \%$. The results show an enhancement in the heat transfer with addition of nanoparticles in base fluid with increase in effective thermal conductivity of the solution.

A low Richardson number governs the forced convection and leads to steep and crowded isotherms near the vicinity of heater walls. This results in a high temperature gradient and subsequently high heat flux through the heater wall. The wall heat flux at bottom heater is always more than the left heater because the acceleration of flow over the bottom heater surface. It is observed that increase in heater size leads to the increase in the Nusselt number.

Average Nusselt number on the lid wall is seen to be increasing with the increase in the volume fraction of nanoparticle and decrease in Richardson number.

\section{ACKNOWLEDGEMENT}

The authors would like to acknowledge the research facility and supports provided by the Department of Mechanical Engineering and computer center at National Institute of Technology Durgapur, India.

\section{REFERENCES}

[1] Brinkman HC. (1952). The viscosity of concentrated suspensions and solutions. The Journal of Chemical $\begin{array}{lll}\text { Physics } & \text { 20(4): 571-571. }\end{array}$ http://dx.doi.org/10.1063/1.1700493

[2] Maxwell JC. (1873). Electricity and Magnetism Clarendon Press.

[3] Choi SUS, Jeffrey A. (1995). Eastman. Enhancing thermal conductivity of fluids with nanoparticles. No. ANL/MSD/CP--84938; CONF-951135--29. Argonne National Lab., IL, United States.

[4] Chao PKB, et al. (1983). Laminar natural convection in an inclined rectangular box with the lower surface halfheated and half-insulated. Journal of heat transfer 105(3): 425-432. http://dx.doi.org/10.1115/1.3245602

[5] Chu HHS, Churchill SW, Patterson CVS. (1976). The effect of heater size, location, aspect ratio, and boundary conditions on two-dimensional, laminar, natural convection in rectangular channels. Journal of Heat Transfer 98(2): 194-201. http://dx.doi.org/10.1115/1.3450518

[6] Oztop HF, Eiyad AN. (2008). Numerical study of natural convection in partially heated rectangular enclosures filled with nanofluids. International Journal of Heat and Fluid Flow 29(5): 1326-1336. http://dx.doi.org/10.1016/j.ijheatfluidflow.2008.04.009

[7] Hasnaoui M, Bilgen E, Vasseur P. (1992). Natural convection heat transfer in rectangular cavities partially heated from below. Journal of Thermophysics and Heat Transfer 6. http://dx.doi.org/10.2514/3.353

[8] Ahmed GR, Yovanovich M. (1992). Numerical study of natural convection from discrete heat sources in a vertical square enclosure. Journal of Thermophysics and Heat Transfer 6(1): 121-127. http://dx.doi.org/10.2514/3.326

[9] Türkoglu H, Nuri Y. (995). Effect of heater and cooler locations on natural convection in square cavities. Numerical Heat Transfer, Part A: Applications 27(3): 351-358.

[10] Aydin O, Yang WJ. (2000). Natural convection in enclosures with localized heating from below and symmetrical cooling from sides. International Journal of Numerical Methods for Heat \& Fluid Flow 10(5): 518529. http://dx.doi.org/10.1108/09615530010338196

[11] Nasr KB, et al. (2006). Numerical study of the natural convection in cavity heated from the lower corner and cooled from the ceiling. Applied Thermal Engineering 26(7): 772-775.

[12] Ishihara I, Fukui T, Matsumoto R. (2002). Natural convection in a vertical rectangular enclosure with symmetrically localized heating and cooling zones. International Journal of Heat and Fluid Flow 23(3): 366372. http://dx.doi.org/10.1016/S0142-727X(02)00184-4

[13] Varol Y, Ahmet K, Hakan FO. (2006). Natural convection in a triangle enclosure with flush mounted heater on the wall. International Communications in Heat and Mass Transfer 33(8): 951-958. http://dx.doi.org/10.1016/j.icheatmasstransfer.2006.05.0 03

[14] Koca A, Hakan FO, Yasin V. (2007). The effects of Prandtl number on natural convection in triangular enclosures with localized heating from below. International Communications in Heat and Mass Transfer 34(4): 511-519. http://dx.doi.org/10.1016/j.icheatmasstransfer.2007.01.0 06

[15] Farouk BAKHTIER, Fusegi TORU. (1989). Natural convection of a variable property gas in asymmetrically heated square cavities. J. Thermophy. Heat Transfer 3 . http://dx.doi.org/10.2514/3.130

[16] Fluent A. (2009). 12.0 Theory Guide. Ansys Inc 5.

[17] Talebi F, Amir HM, Mina S. (2010). Numerical study of mixed convection flows in a square lid-driven cavity utilizing nanofluid. International Communications in Heat and Mass Transfer 37(1): 79-90. http://dx.doi.org/10.1016/j.icheatmasstransfer.2009.08.0 13

[18] De Vahl DG. (1983). Natural convection of air in a square cavity: a bench mark numerical solution. International Journal for Numerical Methods in Fluids 3(3): 249-264. http://dx.doi.org/10.1002/fld.1650030305 
[19] Ahrar AJ, Djavareshkian MH, Ataiyan M. (2017). Numerical simulation of $\mathrm{Cu}$-water nanofluid magnetohydro-dynamics and heat transfer cavity containing a circular cylinder of different size and positions. International Journal of Heat and Technology 35. http://dx.doi.org/10.18280/ijht.350225

\section{NOMENCLATURE}

b

$\mathrm{C}_{\mathrm{p}}$

g

$\mathrm{Gr}$

$\mathrm{h}$

$\mathrm{k}$

$\mathrm{L}$

$\mathrm{Nu}$

$\mathrm{p}$

$\operatorname{Pr}$

$\operatorname{Re}$

$\mathrm{Ri}$

$\mathrm{T}$

$\mathrm{u}, \mathrm{v}$

acceleration $\left(\mathrm{m} / \mathrm{s}^{2}\right)$
U,V

$\mathrm{U}_{0}$

$\mathrm{X}, \mathrm{y}$

$\mathrm{X}, \mathrm{Y}$

Greek symbols

Length of the heater $(\mathrm{m})$

Heat capacitance

Gravitational

Grashof number

Heat transfer coefficient

$\left(\mathrm{W} / \mathrm{m}^{2} \mathrm{~K}\right)$

Thermal conductivity

(W/m K)

Length of square lid

driven cavity (m)

Nusselt number

Pressure (N/m²)

Prandtl number

Reynolds number

Richardson number

Temperature (K)

Velocity components

$(\mathrm{m} / \mathrm{s})$

$\alpha$

$\beta$

$\mu$

$\theta$

v

$\rho$

$\phi$

\section{Subscripts}

avg

$\mathrm{c}$

$\mathrm{h}$

f

$\mathrm{s}$
Dimensionless velocity components

Lid velocity $(\mathrm{m} / \mathrm{s})$

Cartesian coordinates

(m)

Dimensionless Cartesian coordinates

nf
Thermal diffusivity $\left(\mathrm{m}^{2} / \mathrm{s}\right)$

Thermal expansion coefficient $(1 / \mathrm{K})$

Dynamic viscosity $\left(\mathrm{Ns} / \mathrm{m}^{2}\right)$

Dimensionless temperature

Kinematic viscosity $\left(\mathrm{m}^{2} / \mathrm{s}\right)$

Density $\left(\mathrm{kg} / \mathrm{m}^{3}\right)$

Nanoparticle

concentration

Average

cold

Hot

Base fluid

Solid

Nanofluid 